\title{
Selective attention: The site of the filter in the Identification of language
}

\author{
J. M. WILDING and G. UNDERWOOD, Bedford College, \\ University of London, London, England
}

Subjects shadowed a passage of prose delivered to the right ear and were asked to tap to occurrences of a target in a second passage delivered to the left ear. Group 1 was asked to tap to occurrences of a vowel sound, Group 2 to occurrences of a word, Group 3 to occurrences of a member of a conceptual class of words. The items fulfilling these specifications were identical for all groups, as were the passages. Performance declined from Group 1 to Group 2 and from Group 2 to Group 3.

The experiment reported here is concerned with two questions: (a) Can word identification be regarded as a series of operations proceeding from analysis of physical characteristics to analysis of meaning (Treisman, 1964; Treisman \& Geffen, 1967)? (b) If so, is Treisman correct in postulating a single selective attention "filter" and in placing it between the analysis of physical characteristics and the analysis of semantic content?

Treisman's theory predicts that when separate messages are delivered to the two ears and one has to be repeated back (shadowed) by the listener, targets in the unshadowed message which are specified by a physical feature will be detected, but not targets specified by a semantic feature. If the alternative theory of Deutsch \& Deutsch (1963) is correct, that all inputs are fully analyzed and selection occurs after this, the manner of specifying the target should not affect detection performance.

\section{METHOD}

Subjects shadowed one message delivered to the right ear and had to tap to target words which they were told might occur in either message but which in fact occurred only in the unshadowed message. The type of analysis required to identify these targets was varied solely by the description of the target provided in the instructions.

The messages were modified extracts from For Whom the Bell Tolls by Hemingway, 300 words long, and recorded by a female speaker. The passage to be shadowed started first. The target word occurred four times in context in the unshadowed passage only and was "steel" for half the Ss and "grey" for the others. Words containing the same vowel sound as the target word and names of other metals or colors were removed from both shadowed and unshadowed passages.

Thirty Ss took part; they were volunteer students, including first-year psychologists, 22 females and 8 males. They first practised shadowing a message delivered to the right ear with no message to the left ear. A second practice trial with messages to both ears followed, in which they were required to tap to the word "tanks," which they were told might occur in either message, but which in fact occurred four times in the unshadowed message only.

For the experiment the Ss were divided into three equal groups at random. Group 1 ("steel") was instructed: "I want you to listen for any words which have an 'eel' sound, for instance 'meal,' 'peel,' 'heel,' 'steel,' ‘wheel,' 'deal,' and to tap with the ruler, as before, if you hear such a word in either ear. However, I don't want you to start listening with your teft ear to the other message. Pay close attention to the message in your right ear. So you are to tap with the ruler if you hear a word rhyming with 'eel,' but the most important thing is that you repeat back the passage in your right ear as you hear it."
For Group 2 the instruction identifying the target was: "I also want you to listen for the word 'steel,' as in 'iron and steel, ....," and for Group 3 it was: "I also want you to listen for the name of any metal, for instance 'iron,' 'lead,' 'copper,' 'steel,' 'brass,' 'tin' ...." Apart from a corresponding alteration in the final sentence, the remainder of the instructions were identical with those for Group 1. Similar instructions were given to the groups which had "grey" as the target, Group 1 being asked to identify the vowel sound, Group 2 the word, and Group 3 any colors.

$$
\text { RESULTS }
$$

The mean number of words detected is shown in Table 1. The data were analyzed for trend by Kendall's tau test, employing a correction for ties (Kendall, 1955), a separate analysis being carried out for each word. For "steel" an S of 54 was obtained $(p<0.002)$, and for "grey" an $S$ of 40 (p<0.02).

Table 1

Mean Target Detection Rate and Range of Scores Out of Four Target Words Occurring in the Unshadowed Mesange

\begin{tabular}{|c|c|c|c|}
\hline & Group 1 & Group 2 & Group 3 \\
\hline "Steel" & $\begin{array}{l}2.4(1-4) \\
1.2(1-2)\end{array}$ & $\begin{array}{l}0.8(0-2) \\
0.8(0-1)\end{array}$ & $\begin{array}{l}0.2(0-1) \\
0.2(0-1)\end{array}$ \\
\hline
\end{tabular}

\section{DISCUSSION}

This result refutes the theory of Deutsch \& Deutsch and partially confirms that of Treisman. It also shows that the position of the filter is not adjustable to suit the task. Treisman's theory, however, predicts no difference between Groups 2 and 3, since both are analyzing for features handled after the filter; both should differ significantly from Group 1. An alternative possibility is that in this situation Group 2 performs like Group 1, by scanning for the vowel sound then rescanning the memory trace when it is detected to determine whether the vowel was accompanied by the appropriate consonant. This theory predicts that Groups 1 and 2 will not differ significantly, since they both analyze for features handled before the filter; both should differ significantly from Group 3.

The results do not entirely accord with either of these single-filter theories. A Mann-Whitney $U$ test showed that Groups 1 and 2 differed significantly on "steel" $(p<0.04)$ but not on "grey" $(p<0.50)$. To compare Groups 2 and 3 both words were combined, since the differences were negligible; the Mann-Whitney test yielded a difference significant at the 0.006 tevel. All tests were two-tailed and no correction for ties was included (this would decrease the probability values slightly).

These results suggest either that Treisman's theory of a single filter is incorrect and that progressive filtering occurs, or that Group 2 did perform in the alternative manner suggested above, but had difficulty in discriminating consonants, which contain less energy and are shorter than yowels. The difference between "steel" and "grey" in Group I is not, however, support for an explanation of performance in terms of intensity, since there was no systematic difference in intensity between the two words; both varied considerably in intensity from occurrence to occurrence. 
REFERENCES

DEUTSCH, J. A., \& DEUTSCH, D. Attention: Some theoretical considerations. Psychological Review, 1963, 70, 80-90.

KENDALL, M. G. Rank correlation methods (2nd ed.). London: Griffin, 1955.
TREISMAN, A. M. Selective attention in man. British Medical Bulletin, $1964,20,12-16$.

TREISMAN, A. M., \& GEFFEN, G. Selective attention: Perception or response? Quarterly Journal of Experimental Psychology, 1967, 19, 1-17. 